OPEN ACCESS

Edited by:

Licy L. Yanes Cardozo, University of Mississippi Medical

Center, United States

Reviewed by:

Dulce Elena Casarini,

Federal University of São Paulo, Brazil

Giovanni Vitale,

Istituto Auxologico Italiano (IRCCS),

Italy

Bo Chen,

Sichuan University, China

*Correspondence:

Yue Hu

huyue886420@126.com

${ }^{+}$These authors share first authorship

Specialty section:

This article was submitted to Translational Endocrinology,

a section of the journal

Frontiers in Endocrinology

Received: 18 June 2021 Accepted: 20 September 2021

Published: 22 October 2021

Citation:

Hu Y, Liu L and LuX (2021) Regulation of Angiotensin-Converting

Enzyme 2: A Potential Target to Prevent COVID-19?

Front. Endocrinol. 12:725967. doi: 10.3389/fendo.2021.725967

\section{Regulation of Angiotensin- Converting Enzyme 2: A Potential Target to Prevent COVID-19?}

\author{
Yue $\mathrm{Hu}^{\star \dagger}$, Lihuan Liu ${ }^{\dagger}$ and Xifeng Lu \\ Department of Physiology, Basic Medical College, Shenzhen University, Shenzhen, China
}

The renin-angiotensin system (RAS) is crucially involved in the physiology and pathology of all organs in mammals. Angiotensin-converting enzyme 2 (ACE2), which is a homolog of ACE, acts as a negative regulator in the homeostasis of RAS. ACE2 has been proven to be the receptor of severe acute respiratory syndrome coronavirus 2 (SARS-CoV-2), which caused the coronavirus disease 2019 (COVID-19) pandemic. As SARS-CoV-2 enters the host cells through binding of viral spike protein with ACE2 in humans, the distribution and expression level of ACE2 may be critical for SARS-CoV-2 infection. Growing evidence shows the implication of ACE2 in pathological progression in tissue injury and several chronic conditions such as hypertension, diabetes, and cardiovascular disease; this suggests that ACE2 is essential in the progression and clinical prognosis of COVID-19 as well. Therefore, we summarized the expression and activity of ACE2 under various conditions and regulators. We further discussed its potential implication in susceptibility to COVID-19 and its potential for being a therapeutic target in COVID-19.

Keywords: SARS-CoV-2, COVID-19, angiotensin-converting enzyme 2, renin-angiotensin system, therapeutic target

\section{INTRODUCTION}

Coronavirus disease 2019 (COVID-19) is an acute respiratory disease caused by severe acute respiratory syndrome coronavirus 2 (SARS-CoV-2) (1). It was first reported in December 2019 in Wuhan, Hubei Province of China; as of March 24, 2021, it has resulted in more than 100 million infections and 3.48 million deaths worldwide. SARS-CoV-2 is predominantly transmitted through direct contact or respiratory droplets in a proximity- and time-dependent manner, and it often requires close contact of within 6 feet over a period of 15 min or longer (2). Common COVID-19 symptoms include fever, dry cough, fatigue, and dyspnea, whereas severe symptoms are accompanied by systemic infection and pneumonia because the lungs are the primary target of the disease (3). The disease also causes damages to other organs such as the heart, liver, and kidneys as well as organ systems such as the intestinal, circulatory, and immune systems. Infected patients experience different symptoms to different degrees, ranging from asymptomatic, mild respiratory infections to severe acute respiratory syndrome, which results in organ failure, shock, acute respiratory distress symptoms, heart failure, arrhythmias, renal failure, and eventually death (4). 
Angiotensin-converting enzyme 2 (ACE2) has been reported to be a potent negative regulator of the renin-angiotensin system (RAS), which encodes protein as a functional receptor for the spike glycoprotein of the human coronaviruses SARS, SARS$\mathrm{CoV}-2$, and $\mathrm{HCoV}-\mathrm{NL} 63$, and it is a key pathogenic factor for coronavirus infection in host cells $(5,6)$. In the RAS, ACE2 degrades angiotensin (Ang) II and converts it into Ang-(1-7), which is a vasodilative, antiproliferative, and antiapoptotic agent (7). Thus, the balance between Ang I/Ang II and Ang-(1-7)/Ang(1-9) in the RAS is disrupted by the combination of coronaviral spike glycoprotein and ACE2 (8), which changes the permeability of cell membranes and leads to organ damage. In particular, SARS-CoV-2 infects type II alveolar epithelial cells through ACE2, thus inducing lung injury (9). The virus then continues to invade the cells of other organs such as the heart, kidney, liver, and intestine by binding the ACE2 receptor through blood circulation; this triggers an excessive immune response, which produces numerous inflammatory cytokines and an imbalance in T-helper-1 and T-helper-2 cells, thus causing a cytokine storm and ultimately leading to multiple organ dysfunction syndrome (10).

As mentioned above, the entry of SARS-CoV-2 into host cells is facilitated through the binding of the viral spike protein with the extracellular domains of the transmembrane ACE2 proteins, resulting in the downregulation of surface ACE2 expression (11). Clinical research has indicated a direct link between the downregulation of tissue ACE2 and the imbalance of the RAS in patients with COVID-19, which promotes the development of multiorgan injuries caused by SARS-CoV-2 infection (12). Because of the crucial role of ACE2 in SARS-CoV-2 infection, potential therapeutic strategies include the prevention of the binding of human ACE2 and the receptor-binding domain of the viral spike protein or the direct and indirect regulation of ACE2 expression, small molecule inhibitors, drugs, ACE2 antibodies, or single-chain antibody fragments against ACE2, which may influence its activity. In addition, a novel strategy for the rapid detection of SARS-CoV-2 has been reported (13), which is based on the function of ACE2 as a receptor of the spike protein and detects samples in a lateral flow immunoassay without DNA extraction and quantitative reverse transcriptase-polymerase chain reaction.

Therefore, understanding the expression and activity of ACE2 regulation in various conditions may help predict SARS-CoV-2 infection in patients with COVID-19 under different conditions and clinical prognosis. In this review, we summarize the regulation of ACE2 expression and activity under various conditions and regulators and discuss its role as a potential therapeutic target in COVID-19.

\section{RAS AND ACE}

The RAS is a major regulator of blood pressure and fluid homeostasis (Figure 1). It interacts with the kallikrein-kinin system and plays a key role in the cardiovascular system (14). Renin cleaves angiotensinogen to form Ang I, which is then cleaved by ACE to generate Ang II. Ang II can bind to Ang II type 1 and 2 receptors (AT1/2R) and induce vessel contraction and increase blood pressure, thus acting as an effector of the RAS $(15,16)$. A homolog of ACE, ACE2, was discovered approximately two decades ago (17). This homolog is a single transmembrane protein with 805 amino acids, containing a HEXXH zinc-binding domain that is homologous to the enzyme activity site of ACE, sharing $42 \%$ similarities with ACE at the amino acid level (18). However, ACE2 is insensitive to classic ACE inhibitors (ACE-Is) such as captopril, and it plays a role completely opposite to that of ACE (19). ACE2 can recognize Ang I and cleave it into Ang-(1-9), which is quickly converted to Ang-(1-7) by ACE (19, 20). Moreover, ACE2 isolated from the human heart only hydrolyzes Ang II but not Ang I. These findings suggest that Ang II is the preferred substrate of ACE2 (21). Thus, ACE2 can act as an antagonist of ACE functions by degrading Ang II and its consequent vasoconstrictive effects. Furthermore, Ang-(1-7) has been identified as a ligand for Mas receptor, which is a seventransmembrane G-protein-coupled receptor. Upon ligand binding, Mas receptor induces intracellular signaling cascades, including the activation of protein kinase $\mathrm{B}$ and induction of nitric oxide production, exerting vasoprotective functions in contrast to the hypertensive and proliferative functions of Ang II-AT1R/AT2R axis (22). Moreover, ACE2 can act on not only the RAS but also several peptides from other systems, such as neurotensin (1-14), apelin13, dynorphin (1-14), and some of the kinin metabolites $(23,24)$.

Unlike the ubiquitous expression of ACE, ACE2 is predominantly expressed in the heart, kidneys, and testes. However, ACE2 expression can also be observed in the gastrointestinal tract, lungs, and liver but to a lesser extent. In general, genetic deletions of ACE2 impair cardiovascular functions, but the exact impacts are various. Crackower et al. (25) found that ACE2 deficiency severely reduces cardiac contractility but it does not affect blood pressure, whereas Gurley et al. (26) reported that ACE2 knockout (KO) mice showed no changes in the cardiac structure or function; however, they showed slight increases in blood pressure. Moreover, ACE2 KO mice were shown to be more susceptible to Ang II-induced hypertension (26). In addition to its effects on the cardiovascular system, ACE2 deficiency influences the functions of the liver, whereas its expression is relatively abundant. In addition, ACE2 $\mathrm{KO}$ mice have been reported to show abnormal lipid accumulation in the liver and impaired glucose metabolism (27). Furthermore, ACE2 plays a protective role against liver damage; the loss of ACE2 function in the liver may accelerate the development of liver injury such as liver fibrosis (28). In the lungs, ACE2 is primarily expressed in epithelial cells. Deleting ACE2 does not impair lung functions but augments lung injury induced by cigarette smoke exposure, which is likely to be due to the increased activation of matrix metalloproteinases.

ACE2 plays a crucial role in avian influenza H5N1 and H7N9 virus infections as well as in SARS-CoV and SARS-CoV-2 infections (Figure 2A). Furthermore, ACE2 deficiency 
The RAS system

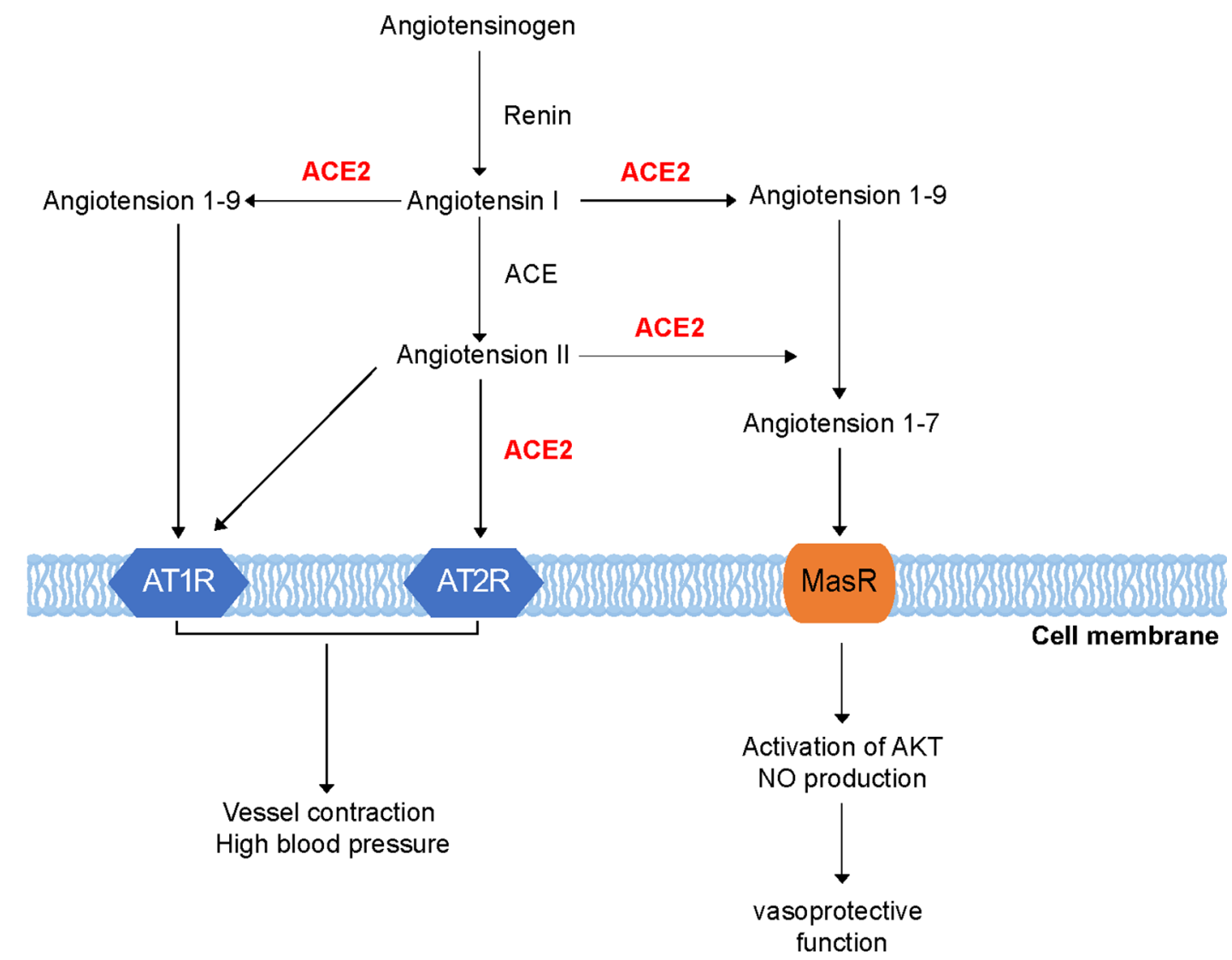

FIGURE 1 | Renin-angiotensin system. Renin cleaves angiotensinogen to form Ang I, which is then cleaved by angiotensin-converting enzyme (ACE) to generate Ang II. Ang II can bind to Ang II type 1 and 2 receptors (AT1/2R). ACE2 is a single transmembrane protein, which can recognize Ang I and cleave it into Ang 1-9, which is quickly converted to Ang 1-7 by ACE. Moreover, Ang-(1-7) has been identified as a ligand for Mas receptor, which is a seven-transmembrane G-protein coupled receptor. Mas receptor may induce intracellular signaling cascades such as protein kinase B and induction of nitric oxide (NO) production.

increases the severity of H7N9-virus-induced lung injury, which may be attenuated by blocking AT1R, suggesting that enhanced Ang II/ATR1 signaling is a major cause of lung injury during infection with the avian influenza virus. Notably, although ACE2 receptor mediates virus infection, both SARS-CoV and H7N9 virus downregulate its expression in the lungs shortly after viral infection; however, the expression of ACE remains unaffected. Thus, it is not surprising that serum Ang II levels were increased in patients with $\mathrm{H} 5 \mathrm{~N} 1$ and $\mathrm{H} 7 \mathrm{~N} 9$ infection. Moreover, the administration of human recombinant ACE2 protein reduces lung injury induced by the avian influenza H5N1 virus $(29,30)$.

\section{SOLUBLE ACE2 AND RECOMBINANT ACE2}

In addition to membrane-bound ACE2, a soluble form of ACE2 (sACE2) also exists in circulation. ACE2 may be constitutively cleaved to release two distinct major soluble forms.
The deglycosylated molecular masses of the larger and smaller soluble forms are approximately 80 and $70 \mathrm{kDa}$, respectively (31). A $70-\mathrm{kDa}$ ACE2 was purified from astrocyte cell culture, which converted Ang II into Ang-(1-7), suggesting that this protein is a secreted form of the enzyme (32). A 60-kDa sACE2 was also purified from the mesangial cells from mice, which generated Ang-(1-7) from Ang II that prevented exposures to high levels of this vasoconstrictive peptide and exert a protective effect in renal hemodynamics (33). Because sACE2 contains a completely catalytic domain, it may still be capable of cleaving Ang II in circulation. Circulating sACE2 activity levels have been associated with chronic systolic heart failure in humans, and after intensive medical therapy, increases in baseline serum sACE2 levels have predicted a significant reduction in the risk of death after cardiac transplantation (34).

sACE2 is enzymatically active and partially inhibits virus entry into the target cells of human airway epithelia. Mutant and chimeric ACE2 proteins showed that a point mutation in the ACE2 ectodomain, L584A, markedly attenuated shedding. The 
resultant ACE2-L584A mutant trafficked to the cell membrane and facilitated SARS-CoV entry into target cells, suggesting that the ACE2 ectodomain regulates its release and that residue L584 might be part of a putative sheddase "recognition motif". Both wild-type ACE2 and the ACE2-L584A mutant supported productive infection with the SARS-CoV, indicating that sACE2 generation is not required for the protein to function as a coronavirus receptor (35). Soluble recombinant ACE2 (rACE2) has been reported to prevent the rapid hypertension elicited by Ang II by reducing its level and increasing Ang-(1-7) level in plasma, and during Ang II infusion, rACE2 degraded Ang II and thus normalized blood pressure (36). Thus, rACE2 may provide a novel therapeutic target and be used as a potential antihypertensive drug. Notably, ADAM17, which is a disintegrin and metalloprotease 17, cleaves ACE2 between Arg (708) and Ser (709), forming a 20-amino acid transmembrane peptide (37). The binding of Ang II with AT1R can promote sACE2 formation by increasing ADAM17 activity (38), which generates sACE2, reducing surface ACE2 expression (Figure 2B). We suggest that rACE2 can be important in SARS-CoV-2 treatment.

Overall, on the basis of the known molecular functions of the RAS, ACE2 and related genes play central roles in the RAS activity, associated pathologies, and virus infection, including the global pandemic, COVID-19. Thus, it is extremely necessary and useful to summarize the regulators of ACE2 for further research.

\section{TRANSCRIPTIONAL AND TRANSLATIONAL REGULATION OF ACE2}

\section{Transcription Factor Regulation}

Similar to other components of the RAS, ACE2 expression is also well regulated to maintain appropriate RAS activities. Ang II can suppress ACE2 expression via AT1R in neuronal cells, forming a negative feedback loop. Ang-(1-7) can antagonize the Ang IIinduced downregulation of ACE2 expression, although it does not influence ACE2 expression in neuronal cells. It has been revealed that the regulation of ACE2 by Ang II/AT1R requires sequences to lie between 481 and 516 base pairs upstream of the transcription initiation site of human ACE2; although the exact transcription factor (TF) mediating Ang II/AT1R-regulated ACE2 expression is yet to be identified, it is evident that the ATTTGGA motif, which is a binding sequence for TF Ikaros, is indispensable for this regulation (39). There are also three binding sites that are highly conserved in mammals for hepatic nuclear factor 1 (HNF1), which is a TF that regulates various hepatic genes and plays an important role in homeobox gene family expression of the liver and kidney. Knocking out HNF1 in mice induces death around weaning after a progressive wasting syndrome with a markedly enlarged liver (40). Both HNF1 $\alpha$ and HNF1 $\beta$ can increase ACE2 expression in insulin-producing cells, including pancreatic $\beta$ cells and insulinoma cells. Notably, HNF1 $\alpha$ increases ACE2 gene expression in primary cells from pancreatic islets through evolutionarily conserved motifs in the proximal promoter region (41). In addition, $\mathrm{HNF} 4 \alpha-\mathrm{a}$ master regulatory protein in the liver and an important TF in angiotensinogen gene regulation-targets ACE2 and influences its mRNA expression (42).

Hypoxia-inducible factor 1 (HIF-1) is a heterodimeric TF comprising a regulatory $\alpha$ subunit (HIF-1 $\alpha$ ) and a constitutive $\beta$-subunit (HIF-1 $\beta$ ) (43). Notably, HIF- $1 \alpha$ indirectly regulates ACE2 through the downregulation of ACE2 expression for the accumulation of Ang II catalyzed by ACE. The expression levels of ACE2 mRNA increase during the early stages of hypoxia and decrease to near baseline levels at the later stages after HIF-1 $\alpha$ accumulation in pulmonary artery smooth muscle cells. Therefore, direct regulation of $\mathrm{ACE}$ and bidirectional regulation of ACE2 by HIF- $1 \alpha$ during hypoxia could play a protective role during the development of hypoxic pulmonary hypertension (44).

\section{Epigenetic Regulation}

Except for the TF, epigenetic regulation could also occur in ACE2 mRNA expression, such as the regulation of histone acetylase/deacetylase and microRNAs. Silent information regulator $\mathrm{T} 1$ is a histone deacetylase and a transcriptional mediator, which exerts protective effects via the deacetylation of its target proteins such as proteins involved in cellular stress resistance and genomic stability. Silent information regulator T1 binds to the ACE2 promoter; this binding may increase after treatment with the antimicrobial peptide mimic 5aminoimidazole-4-carboxamide ribonucleotide (AICAR) in Huh7 cells, which increases ACE2 mRNA expression levels under the hypoxic conditions induced. In contrast, the inhibition of Silent information regulator T1 activity eliminates the 5-aminoimidazole-4-carboxamide ribonucleotide-induced increase in ACE2 expression (45). The ACE2 mRNA expression level increases by increasing the occupancy of histone $\mathrm{H} 3$ acetylation, which binds on ACE2 promoter region in rabbit models of high-cholesterol diet-induced atherosclerosis treated with atorvastatin. Additionally, the epigenetic regulation of ACE2 may be another realistic way to treat atherosclerosis and cardiovascular disorders (46).

MicroRNAs are endogenous, small (19-25 nucleotides), and non-coding RNAs, which can target specific genes and function as the negative regulators of gene expression by inhibiting the translation of or promoting the degradation of targeted mRNAs. The role of microRNAs in regulating the standard and novel cardiac RAS during aerobic exercise training in rats with left ventricular hypertrophy has indicated that exercise can increase miRNA-27a and miRNA-27b targeting ACE and miR-143 targeting ACE2, inducing higher mRNA expression and protein levels of ACE2, followed by an increase in Ang-(1-7) and AT2R (47) levels. Additionally, in patients with uremia, circulating miR-421 shows enhanced higher expression than that in healthy individuals; it targets leucocytic ACE2 and decreases its transcripts. The association between miR-421 and ACE2 may contribute to lower expression of the enzyme in the leukocytes of chronic kidney diseases, further supporting the development of atherosclerotic events (48), which suggests that miRNA can also be a target for atherosclerosis. In cardiovascular disease, miR-421 could be a potential regulator of ACE2 involved in the 
The roles of ACE2 in SARS-CoV and SARS-CoV-2 infection

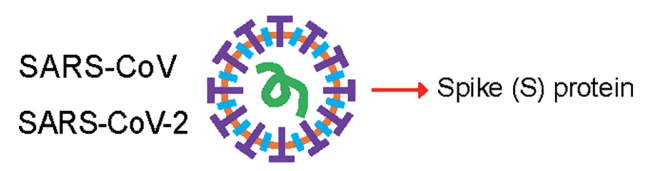

A

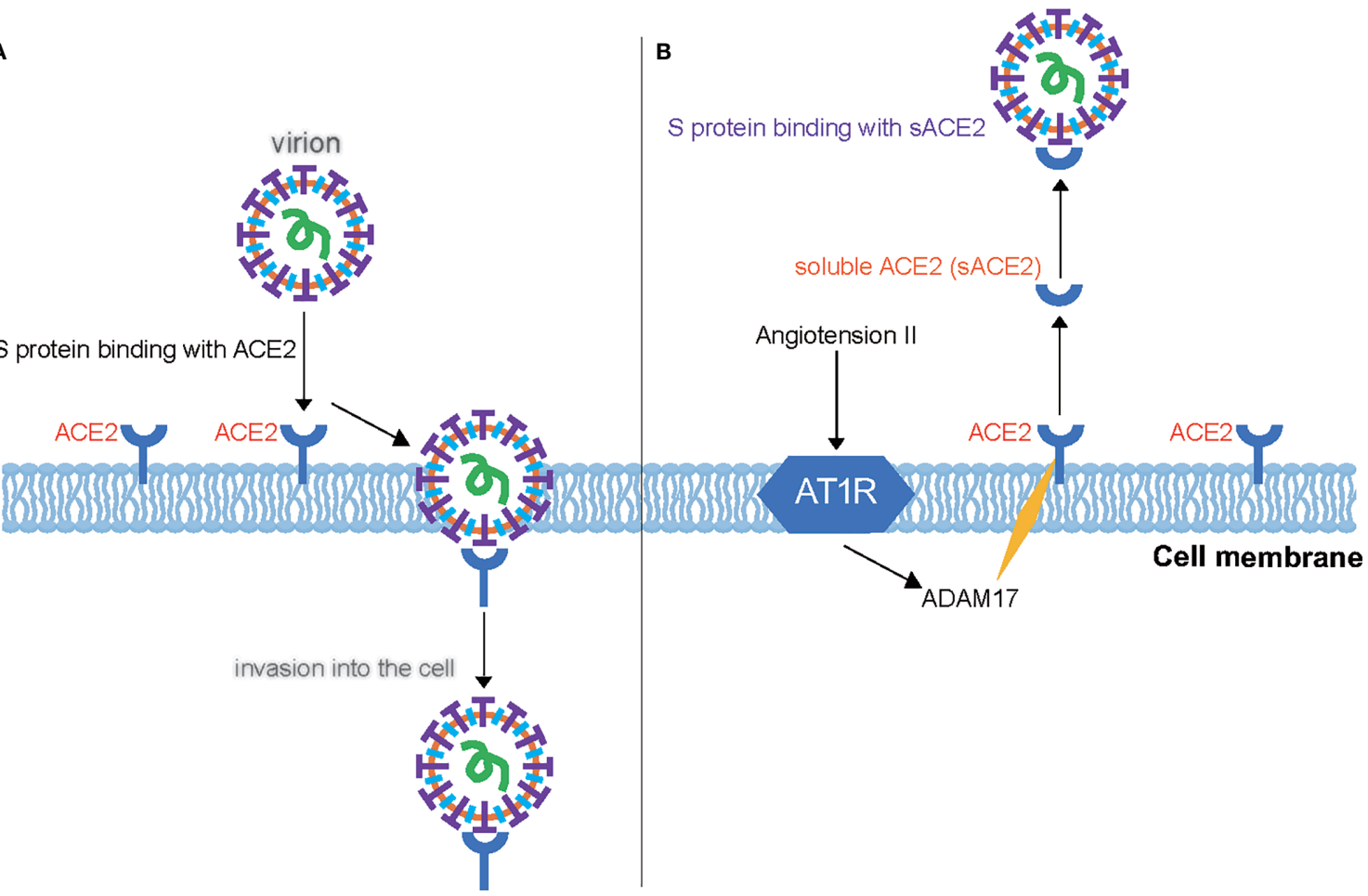

FIGURE 2 | Roles of angiotensin-converting enzyme 2 (ACE2) in severe acute respiratory syndrome coronavirus (SARS-CoV) and SARS-CoV-2 infection. (A) ACE2 acts as the key receptor in avian influenza H5N1 and H7N9 virus infections as well as in SARS-CoV and SARS-CoV-2 infections. (B) Roles of a soluble form of angiotensin-converting enzyme 2 (SACE2) and A disintegrin and metalloprotease 17 (ADAM17) in cells infected with SARS-CoV and SARS-CoV-2. ADAM17 cleaves ACE2 and forms a 20-amino acid transmembrane peptide. The binding of Ang II with AT1R promotes SACE2 formation by increasing ADAM17 activity, which generates SACE2 and binds to the spike protein of SARS-CoV-2 as the virus receptor.

development of thrombosis and downregulation of its protein level in both primary cardiac myofibroblasts and transformed cells. Notably, miR-421 levels show significant interpatient variabilities, which are consistent with the alteration in ACE2 expression (49).

\section{Regulation by Other Factors}

Several factors regulate ACE2 mRNA expression levels during disease progression. For example, transforming growth factor- $\beta$, which is pivotal in diabetic nephropathy, has a negative feedback effect on the mRNA expression and protein level of ACE2 and its cell membrane-binding receptor Mas. Thus, it can decrease ACE2, Mas, and Ang-(1-7) conversion from Ang II in high glucose-cultured NRK-52E cells, suggesting a possible treatment for diabetic renal fibrosis (50). Additionally, nuclear factor erythroid 2-related factor 2 functions as a master regulator of redox balance in cellular cytoprotective responses. The loss of this factor upregulates the expression of renal proximal tubule cellular ACE2 and its Mas receptor, followed by an increase in urinary Ang-(1-7) levels and downregulation of the expression of angiotensinogen, ACE, and profibrotic genes in Akita mice (51).

Curcumin, a yellow pigment extracted from the rhizomes of Curcuma longa, which exhibits pharmacologic properties such as anti-inflammation and fibrosis properties, increases ACE2 protein levels and enhances its expression in the intermyocardium relative to animals with Ang II infusion (52). Rosiglitazone, which is a peroxisome proliferator-activated receptor gamma ligand that acts as an insulin sensitizer and exerts cardiovascular action, increases ACE2 and Ang-(1-7) protein levels and decreases the Ang II level to lower blood pressure in a peroxisome proliferator-activated receptor gammadependent manner in male Wistar rat models (53).

\section{Regulation by Chinese Medicine}

As mentioned above, ACE2 is an important enzyme that attaches to the cellular membranes in the lungs, arteries, heart, kidney, 
and intestines and functions in the pathophysiology of lung and cardiovascular diseases. Some drugs regulate ACE2 protein levels during disease processes. For example, Yinhenhao decoction is a traditional Chinese medicine that has antifibrotic effects that reduce hepatic fibrogenesis in the bile duct ligation rat liver model. This is achieved by decreasing the standard RAS pathway components and transforming growth factor- $\beta 1$ down expression, which elevates the ACE2 protein level to recover and rebuild self-regulation of the RAS (54). In addition, Sini decoction, which is used widely for treating clinical diseases, alleviates Escherichia coli-induced acute lung injury in mice by markedly enhancing ACE2 protein levels to activate the ACE2Ang-(1-7)-Mas pathway and equilibrate the ACE-Ang II-AT1R and ACE2-Ang-(1-7)-Mas axis (55). Diminazene aceturate, which is the most widely used therapeutic agent for trypanosomiasis and has been shown to prevent pulmonary hypertension, increases the protein level of ACE2 to prevent the progression of asthma by altering the levels of AKT, p38, NF$\kappa \mathrm{B}$, and other inflammatory markers in male Wistar rats (56). Some other regulators such as RAS regulators and drugs influence ACE2 functions at transcriptional and translational levels and its activities.

On the basis of these ACE2 regulators described above, we summarized the available data, including the data regarding their effects on ACE2 through mRNA expression, protein level alteration, and activities in Table $\mathbf{1}$.

\section{PHARMACOLOGICAL REGULATION OF ACE2}

Considering that the primary symptoms of COVID-19 reported to date include hypertension, atherosclerosis, diarrhea, glaucoma, anosmia, ageusia, skin lesions (dermatitis), autoimmune inflammation of the central nervous system, and damage to organs such as the lungs, heart, kidneys, and testicles, all these diffuse COVID-19 disorders are likely associated with an overreaction of the RAS in patients with COVID-19 (57). Current pharmacotherapies aim to inhibit multiple levels of the RAS through distinct modes of action. Because ACE2 is the key negative modulator of the RAS, its gene transcription and translation level and the catalytic activities are modified owing to the intricate nature of the RAS. The presence of several RAS modulators functioning at different levels in this system results in various effects on ACE2. In Table 2, we summarize the major studies, including the effects of various RAS modulators (as drugs) on ACE2 in mRNA expression, protein levels, and activities. The effects elicited by these different drugs on ACE2 depend on several factors, including the various systems studied, disease progression stage, and drug usage.

Although ACE2 is not the direct cellular target of these therapies, ACE2 gene transcription, translation, and catalytic activity are also modified owing to the intricate nature of the RAS. For example, angiotensin-receptor blockers (ARBs) and

TABLE 1 | Transcriptional and translational regulators of angiotensin-converting enzyme 2.

\begin{tabular}{|c|c|c|c|c|}
\hline Class & Gene name & Condition & System & Impact on ACE2 \\
\hline \multirow[t]{3}{*}{$\begin{array}{l}\text { Transcription } \\
\text { factor }\end{array}$} & $\begin{array}{l}\text { Hepatic nuclear factor } 1 \text { (HNF1), } \\
\text { comprising } \mathrm{HNF} 1 \alpha \text { and } \mathrm{HNF} 1 \beta\end{array}$ & Healthy & $\begin{array}{l}\text { In vivo in insulin-producing cells, including } \\
\text { pancreatic } \beta \text { cells and insulinoma cells }\end{array}$ & Increase ACE2 mRNA expression level $(40,41)$ \\
\hline & $\mathrm{HNF} 4 \alpha$ & Healthy & In vivo in the liver of mice & Target ACE2 and affect its mRNA expression level (42) \\
\hline & $\begin{array}{l}\text { Hypoxia-inducible factor } 1 \text { (HIF- } \\
1), \text { comprising HIF- } 1 \alpha \text { and HIF- } \\
1 \beta\end{array}$ & $\begin{array}{l}\text { Hypoxic } \\
\text { pulmonary } \\
\text { hypertension }\end{array}$ & $\begin{array}{l}\text { In vivo in pulmonary artery smooth muscle } \\
\text { cells }\end{array}$ & $\begin{array}{l}\text { Target ACE2 and indirectly decrease ACE2 mRNA } \\
\text { expression level for the accumulation of Ang } \| \\
\text { catalyzed by } \operatorname{ACE}(43,44)\end{array}$ \\
\hline \multirow[t]{5}{*}{$\begin{array}{l}\text { Epigenetic } \\
\text { regulation }\end{array}$} & $\begin{array}{l}\text { Histone deacetylase: silent } \\
\text { information regulator } \mathrm{T} 1\end{array}$ & Hypoxic & In vivo in Huh7 cells & $\begin{array}{l}\text { Bound to the ACE2 promoter and increase ACE2 } \\
\text { mRNA expression level (45) }\end{array}$ \\
\hline & Histone $\mathrm{H} 3$ acetylation & Atherosclerosis & $\begin{array}{l}\text { In the heart of rabbits with high-cholesterol } \\
\text { diet-induced atherosclerosis treated with } \\
\text { atorvastatin }\end{array}$ & $\begin{array}{l}\text { Bound to the ACE2 promoter and increase ACE2 } \\
\text { mRNA expression level (46) }\end{array}$ \\
\hline & MicroRNAs: miR-143 & $\begin{array}{l}\text { Left ventricular } \\
\text { hypertrophy }\end{array}$ & In aerobic exercise training rats & Increase ACE2 mRNA expression and protein level (47) \\
\hline & MicroRNAs: miR-421 & Uremic & Human & $\begin{array}{l}\text { Target leucocytic ACE2 and decrease its transcripts } \\
\text { (48) }\end{array}$ \\
\hline & & Thrombosis & $\begin{array}{l}\text { In both primary cardiac myofibroblasts and } \\
\text { transformed cells }\end{array}$ & Decrease ACE2 protein level (49) \\
\hline \multirow[t]{4}{*}{ Other factors } & Transforming growth factor- $\beta$ & $\begin{array}{l}\text { High-glucose- } \\
\text { cultured }\end{array}$ & In NRK-52E cells & Decrease ACE2 mRNA and protein level (50) \\
\hline & $\begin{array}{l}\text { Nuclear factor erythroid 2- } \\
\text { related factor } 2 \text { (Nrf2) }\end{array}$ & Nrf2 knockout & In Akita mice renal proximal tubule cells & Increase ACE2 expression (51) \\
\hline & Curcumin & $\begin{array}{l}\text { Myocardial } \\
\text { fibrosis }\end{array}$ & In male Sprague-Dawley rats & Increase ACE2 protein level (52) \\
\hline & $\begin{array}{l}\text { Rosiglitazone: a peroxisome } \\
\text { proliferator-activated receptor } \\
\text { gamma ligand }\end{array}$ & Hypertension & In vivo in male Wistar rats & Increase ACE2 protein level (53) \\
\hline \multirow[t]{3}{*}{$\begin{array}{l}\text { Chinese } \\
\text { medicine }\end{array}$} & Yinhenhao decoction & $\begin{array}{l}\text { Hepatic } \\
\text { fibrogenesis }\end{array}$ & $\begin{array}{l}\text { In vivo in the bile duct ligation rat liver } \\
\text { model }\end{array}$ & Increase ACE2 protein level (54) \\
\hline & Sini decoction & $\begin{array}{l}\text { Acute lung } \\
\text { injury }\end{array}$ & In vivo in rats & Increase ACE2 protein level (55) \\
\hline & Diminazene aceturate & Asthma & In vivo in male Wistar rats & Increase ACE2 protein level (56) \\
\hline
\end{tabular}


TABLE 2 | Studies investigating the impacts of several cardiopulmonary diseases and renin-angiotensin system modulators on angiotensin-converting enzyme 2 expression and activity.

\begin{tabular}{|c|c|c|c|c|}
\hline $\begin{array}{l}\text { Drug } \\
\text { class }\end{array}$ & Drugs & Condition & System & Impact on ACE2 \\
\hline \multirow[t]{7}{*}{ ACE-I } & Lisinopril & Healthy & In vivo in rat renal cells & $\begin{array}{l}\text { Decrease in ACE2 mRNA expression (combination with } \\
\text { low-sodium diet) (58) }\end{array}$ \\
\hline & & & In vivo in rat cardiac (LV) cells & Increase in ACE2 mRNA expression (59) \\
\hline & & HTN & In vivo in transgenic Ren2 rats cardiac and renal cells & Increase in ACE2 mRNA expression and activity (60) \\
\hline & Enalapril & $\mathrm{Ml}$ & In vivo in rat cardiac (LV) and plasma cells & $\begin{array}{l}\text { Increase in ACE2 mRNA expression and activity } 8 \text { weeks } \\
\text { post-MI (61) }\end{array}$ \\
\hline & Captopril & ALI & $\begin{array}{l}\text { In vivo in rat pulmonary tissue and in vitro in rat pulmonary } \\
\text { microvascular endothelial cells }\end{array}$ & Increase in ACE2 protein level (62) \\
\hline & Any ACE & Likely & In vivo in human intestinal cells & Increase in intestinal ACE2 mRNA expression (63) \\
\hline & inhibitors & HTN & & \\
\hline \multirow[t]{8}{*}{ ARB } & Losartan & Healthy & In vivo in rat cardiac (LV) cells & Increase in ACE2 mRNA expression and activity (64) \\
\hline & & & In vivo in rat cardiac (LV)/renal cells & $\begin{array}{l}\text { Potentiation of renal upregulation of ACE2 mRNA } \\
\text { expression (65) }\end{array}$ \\
\hline & & ARDS & In vivo in rat BALF & Increase in ACE2 activity (66) \\
\hline & Olmesartan & HTN & In vivo in rat aorta/carotid artery cells & Increase in ACE2 mRNA expression and activity (67) \\
\hline & Irbesartan & Healthy & In vivo in rat aorta cells & $\begin{array}{l}\text { Significantly increase mRNA expression and protein level } \\
\text { (68) }\end{array}$ \\
\hline & Telmisartan & HTN & In vivo in rat cardiac (aorta) cells & Decrease in ACE2 activity (69) \\
\hline & & Healthy & In vivo in rat renal cells & Increase in ACE2 mRNA expression and protein level (70) \\
\hline & Eprosartan & $\mathrm{HF}$ & In vivo in rat cardiac cells & Increase in ACE2 activity (71) \\
\hline \multirow[t]{2}{*}{ MRB } & Eplerenone & Healthy & In vivo in rat peritoneal macrophages/cardiac cells & Increase in ACE2 mRNA expression and activity (72) \\
\hline & Spironolactone & $\mathrm{HF}$ & In vivo in human monocyte-derived macrophages & Increase in ACE2 mRNA expression and activity (72) \\
\hline $\mathrm{RI}$ & Aliskiren & DN & In vivo in rat renal cells & Decrease in ACE2 activity (73) \\
\hline
\end{tabular}

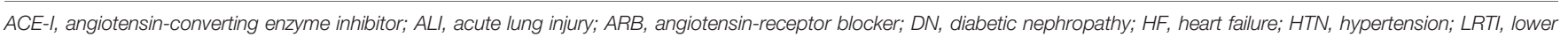
respiratory tract infection; $L V$, left ventricle; MI, myocardial infarction; MRB, mineralocorticoid receptor blocker; Rl, renin inhibitor.

ACE-Is mostly increased ACE2 mRNA expression and protein level in the heart, kidneys, and thoracic aorta, but the activity varies across experimental models and tissues for ACE-Is (Table 2). Lisinopril treatment in healthy rats fed with lowsodium diet decreases the ACE2 mRNA levels in renal cells (58), whereas it increases ACE2 mRNA expression in cardiac cells (59). In addition, lisinopril used in transgenic Ren 2 rats in hypertension increases ACE2 mRNA level and activity in the heart and kidneys (60). Moreover, in other ACE-I treatments, ACE2 mRNA expression and activity are both increased by enalapril in myocardial infarction rat cardiac and plasma cells (61). ACE2 protein levels are increased by captopril in rat pulmonary tissue and pulmonary microvascular endothelial cells in vitro under conditions of acute lung injury (62). Moreover, ACE2 mRNA expression levels were increased in human intestinal cells by any ACE-Is under hypertension condition (63). These findings may be attributed to the tissuespecific regulation of ACE2 as higher ACE2 protein levels were reported in the heart, but ACE2 activity was higher in the kidneys of Sprague-Dawley rats, adding to the complexity of the tissue in the RAS (74). Therefore, the mechanisms behind the augmentation of ACE2 mRNA levels by ACE-Is and ARBs require further characterization. Moreover, mineralocorticoid receptor blockers such as spironolactone, which prevents increases in both ACE and AT1R mRNA levels and the associated increase in AT1R density from aldosterone signaling in cardiomyocytes $(75,76)$, increase ACE2 mRNA expression and activity in monocyte-derived macrophages from patients with chronic heart failure (72). Furthermore, eplerenone increases ACE2 mRNA expression and activity in healthy rat peritoneal macrophages or cardiac cells (72). The renin inhibitor, aliskiren, decreases the ACE2 activity in diabetic nephropathy renal cells (Table 2) (73).

Clinical researchers have reported that patients with COVID19 with these comorbidities of cardiovascular disease, diabetes, and chronic hypertension have been treated with RAS modulators such as ACE-Is, ARBs, mineralocorticoid receptor blockers, and renin inhibitors (77). ACE-Is and ARBs are commonly used therapeutic drugs for hypertension. Animal experiments have revealed that these drugs decrease the systolic pressure in healthy rats and upregulate ACE2 levels (78). However, some researchers still doubt the safety and effect of using these drugs on patients with COVID-19. As ACE2 expression is suppressed in hypertension and may be further deprived by the SARS-CoV-2 upon infection, the application of ARBs may protect against pulmonary injury under careful blood pressure management.

\section{CONCLUSIONS}

Since the discovery of ACE2, progress has been made in elucidating its biochemical actions and fundamental role in cardiovascular diseases and as a receptor for SARS-CoV-2 attachment. ACE2 functions a negative regulator of the RAS by metabolizing Ang II into the beneficial peptide Ang-(1-7); this important biochemical and physiological property is being harnessed as a potential therapeutic target in patients with cardiovascular diseases. The activation of the RAS axis due to the binding of SARS-CoV-2 to ACE2, which leads to the direct 
loss of ACE2 and indirect loss of ACE2 via proteolytic processing and shedding, partly drives the systemic manifestations of COVID-19.

To date, there is no effective drug for the treatment of COVID-19. Although different types of vaccines have been approved to be used worldwide, the number of vaccines is limited and the protection efficiency varies across countries and regions. Therefore, the severity of the COVID-19 pandemic remains intact and the number of infected people keeps increasing, especially in India. Furthermore, at least three types of SARS-CoV-2 mutants have been identified: B.1.1.7, which was first found in the United Kingdom (79); E484K, which was first found in South Africa (80); and the Indian mutant (the delta variant), which has higher transmission efficiency and stronger pathogenicity than other variants of the virus (81). Therefore, effective drugs are urgently required for the treatment of COVID-19, especially for patients with comorbidities such as hypertension, cardiovascular disease, and lung injury. Of note, several drugs are being developed to treat COVID-19, and some of them are in phase 3 of the clinical trial. For example, colchicine (phase 3 ) is investigated to determine whether short-term treatment with colchicine reduces the rate of death and lung complications associated with COVID-19.

\section{REFERENCES}

1. Coronaviridae Study Group of the International Committee on Taxonomy of V. The Species Severe Acute Respiratory Syndrome-Related Coronavirus: Classifying 2019-Ncov and Naming it SARS-CoV-2. Nat Microbiol (2020) 5:536-44. doi: 10.1038/s41564-020-0695-Z

2. Jayaweera M, Perera H, Gunawardana B, Manatunge J. Transmission of COVID-19 Virus by Droplets and Aerosols: A Critical Review on the Unresolved Dichotomy. Environ Res (2020) 188:109819. doi: 10.1016/ j.envres.2020.109819

3. Jiang F, Deng L, Zhang L, Cai Y, Cheung CW, Xia Z. Review of the Clinical Characteristics of Coronavirus Disease 2019 (COVID-19). J Gen Intern Med (2020) 35:1545-9. doi: 10.1007/s11606-020-05762-w

4. Wang T, Du Z, Zhu F, Cao Z, An Y, Gao Y, et al. Comorbidities and MultiOrgan Injuries in the Treatment of COVID-19. Lancet (2020) 395(10228):e52. doi: 10.1016/s0140-6736(20)30558-4

5. Kuba K, Imai Y, Rao S, Gao H, Guo F, Guan B, et al. A Crucial Role of Angiotensin Converting Enzyme 2 (ACE2) in SARS Coronavirus-Induced Lung Injury. Nat Med (2005) 11:875-9. doi: 10.1038/nm1267

6. Zhou P, Yang XL, Wang XG, Hu B, Zhang L, Zhang W, et al. A Pneumonia Outbreak Associated With a New Coronavirus of Probable Bat Origin. Nature (2020) 579:270-3. doi: 10.1038/s41586-020-2012-7

7. Jiang F, Yang J, Zhang Y, Dong M, Wang S, Zhang Q, et al. AngiotensinConverting Enzyme 2 and Angiotensin 1-7: Novel Therapeutic Targets. Nat Rev Cardiol (2014) 11:413-26. doi: 10.1038/nrcardio.2014.59

8. Monteil V, Kwon H, Prado P, Hagelkruys A, Wimmer RA, Stahl M, et al. Inhibition of SARS-CoV-2 Infections in Engineered Human Tissues Using Clinical-Grade Soluble Human Ace2. Cell (2020) 181:905-13.e7. doi: 10.1016/ j.cell.2020.04.004

9. Zhang HB, Penninger JM, Li YM, Zhong NS, Slutsky AS. AngiotensinConverting Enzyme 2 (ACE2) as a SARS-CoV-2 Receptor: Molecular Mechanisms and Potential Therapeutic Target. Intensive Care Med (2020) 46:586-90. doi: 10.1007/s00134-020-05985-9

10. Wang J, Jiang M, Chen X, Montaner LJ. Cytokine Storm and Leukocyte Changes in Mild Versus Severe SARS-CoV-2 Infection: Review of 3939 COVID-19 Patients in China and Emerging Pathogenesis and Therapy Concepts. J Leukoc Biol (2020) 108:17-41. doi: 10.1002/JLB.3COVR0520-272R
Convalescent plasma has been also used in an efficacious therapy to prevent the progression from mild to severe/critical COVID-19.

Although the putative effects of ACE2 downregulation on the cardiovascular system in the course of the COVID-19 pandemic requires more intensive studies, patients with COVID-19 with these comorbidities of cardiovascular disease have already been treated with RAS and ACE2 regulators. Recent research supports continued use of drugs such ARBs or ACE-Is for patients who have been already using these medications before SARS-CoV-2 infection (82). Thus, we speculate that ACE2-based regulation strategies may become one of the most promising approaches for future therapies and improve disease prognosis in COVID-19. This review will serve as a point of reference for the use of these related drugs.

\section{AUTHOR CONTRIBUTIONS}

$\mathrm{YH}$ and XL designed the content. $\mathrm{YH}$ and LL wrote the main manuscript. LL performed the data collection. YH, LL, and XL edited the manuscript. All authors contributed to the article and approved the submitted version.

11. Gross S, Jahn C, Cushman S, Bar C, Thum T. SARS-CoV-2 Receptor ACE2Dependent Implications on the Cardiovascular System: From Basic Science to Clinical Implications. J Mol Cell Cardiol (2020) 144:47-53. doi: 10.1016/ j.yjmcc.2020.04.031

12. Liu Y, Yang Y, Zhang C, Huang F, Wang F, Yuan J, et al. Clinical and Biochemical Indexes From 2019-Ncov Infected Patients Linked to Viral Loads and Lung Injury. Sci China Life Sci (2020) 63:364-74. doi: 10.1007/s11427-020-1643-8

13. Lee JH, Choi M, Jung Y, Lee SK, Lee CS, Kim J. A Novel Rapid Detection for SARS-CoV-2 Spike 1 Antigens Using Human Angiotensin Converting Enzyme 2 (ACE2). Biosens Bioelectron (2021) 171:112715. doi: 10.1016/j.bios.2020.112715

14. Luzi L, Bucciarelli L, Ferrulli A, Terruzzi I, Massarini S. Obesity and COVID19: The Ominous Duet Affecting the Renin-Angiotensin System. Minerva Endocrinol (Torino) (2021) 46:193-201. doi: 10.23736/S0391-1977.20.03402-1

15. Paz Ocaranza M, Riquelme JA, Garcia L, Jalil JE, Chiong M, Santos RAS, et al. Counter-Regulatory Renin-Angiotensin System in Cardiovascular Disease. Nat Rev Cardiol (2020) 17:116-29. doi: 10.1038/s41569-019-0244-8

16. Patel S, Rauf A, Khan H, Abu-Izneid T. Renin-Angiotensin-Aldosterone (RAAS): The Ubiquitous System for Homeostasis and Pathologies. BioMed Pharmacother (2017) 94:317-25. doi: 10.1016/j.biopha.2017.07.091

17. Tipnis SR, Hooper NM, Hyde R, Karran E, Christie G, Turner AJ. A Human Homolog of Angiotensin-Converting Enzyme - Cloning and Functional Expression as a Captopril-Insensitive Carboxypeptidase. J Biol Chem (2000) 275:33238-43. doi: 10.1074/jbc.M002615200

18. Donoghue M, Hsieh F, Baronas E, Godbout K, Gosselin M, Stagliano N, et al. A Novel Angiotensin-Converting Enzyme-Related Carboxypeptidase (ACE2) Converts Angiotensin I to Angiotensin 1-9. Circ Res (2000) 87:E1-9. doi: 10.1161/01.res.87.5.e1

19. Rice GI, Thomas DA, Grant PJ, Turner AJ, Hooper NM. Evaluation of Angiotensin-Converting Enzyme (ACE), its Homologue ACE2 and Neprilysin in Angiotensin Peptide Metabolism. Biochem J (2004) 383:45-51. doi: 10.1042/BJ20040634

20. Vickers C, Hales P, Kaushik V, Dick L, Gavin J, Tang J, et al. Hydrolysis of Biological Peptides by Human Angiotensin-Converting Enzyme-Related Carboxypeptidase. J Biol Chem (2002) 277:14838-43. doi: 10.1074/jbc.M200581200

21. Patel VB, Zhong JC, Grant MB, Oudit GY. Role of the ACE2/Angiotensin 1-7 Axis of the Renin-Angiotensin System in Heart Failure. Circ Res (2016) 118:1313-26. doi: 10.1161/CIRCRESAHA.116.307708 
22. Gironacci MM, Adamo HP, Corradi G, Santos RA, Ortiz P, Carretero OA. Angiotensin (1-7) Induces MAS Receptor Internalization. Hypertension (2011) 58:176-81. doi: 10.1161/HYPERTENSIONAHA.111.173344

23. Bai B, Cai X, Jiang Y, Karteris E, Chen J. Heterodimerization of Apelin Receptor and Neurotensin Receptor 1 Induces Phosphorylation of ERK(1/2) and Cell Proliferation via Galphaq-Mediated Mechanism. J Cell Mol Med (2014) 18:2071-81. doi: 10.1111/jcmm.12404

24. Warner FJ, Smith AI, Hooper NM, Turner AJ. Angiotensin-Converting Enzyme-2: A Molecular and Cellular Perspective. Cell Mol Life Sci (2004) 61:2704-13. doi: 10.1007/s00018-004-4240-7

25. Crackower MA, Sarao R, Oudit GY, Yagil C, Kozieradzki I, Scanga SE, et al. Angiotensin-Converting Enzyme 2 is an Essential Regulator of Heart Function. Nature (2002) 417:822-8. doi: 10.1038/nature00786

26. Gurley SB, Allred A, Le TH, Griffiths R, Mao L, Philip N, et al. Altered Blood Pressure Responses and Normal Cardiac Phenotype in ACE2-Null Mice. J Clin Invest (2006) 116:2218-25. doi: 10.1172/JCI16980

27. Nunes-Souza V, Alenina N, Qadri F, Penninger JM, Santos RA, Bader M, et al. CD36/Sirtuin 1 Axis Impairment Contributes to Hepatic Steatosis in ACE2Deficient Mice. Oxid Med Cell Longev (2016) 2016:6487509. doi: 10.1155/ 2016/6487509

28. Wu HT, Chuang YW, Huang CP, Chang MH. Loss of Angiotensin Converting Enzyme II (ACE2) Accelerates the Development of Liver Injury Induced by Thioacetamide. Exp Anim (2018) 67:41-9. doi: 10.1538/expanim.17-0053

29. Zou Z, Yan Y, Shu Y, Gao R, Sun Y, Li X, et al. Angiotensin-Converting Enzyme 2 Protects From Lethal Avian Influenza A H5N1 Infections. Nat Commun (2014) 5(1):3594-600. doi: 10.1038/ncomms4594

30. Yang $\mathrm{P}, \mathrm{Gu} \mathrm{H}$, Zhao Z, Wang W, Cao B, Lai C, et al. Angiotensin-Converting Enzyme 2 (ACE2) Mediates Influenza H7N9 Virus-Induced Acute Lung Injury. Sci Rep (2014) 4(1):7027-32. doi: 10.1038/srep07027

31. Iwata M, Silva Enciso JE, Greenberg BH. Selective and Specific Regulation of Ectodomain Shedding of Angiotensin-Converting Enzyme 2 by Tumor Necrosis Factor Alpha-Converting Enzyme. Am J Physiol Cell Physiol (2009) 297:C1318-29. doi: 10.1152/ajpcell.00036.2009

32. Gallagher PE, Chappell MC, Ferrario CM, Tallant EA. Distinct Roles for ANG II and ANG-(1-7) in the Regulation of Angiotensin-Converting Enzyme 2 in Rat Astrocytes. Am J Physiol Cell Physiol (2006) 290:C420-6. doi: 10.1152/ ajpcell.00409.2004

33. Aragao DS, Cunha TS, Arita DY, Andrade MC, Fernandes AB, Watanabe IK, et al. Purification and Characterization of Angiotensin Converting Enzyme 2 (ACE2) From Murine Model of Mesangial Cell in Culture. Int J Biol Macromol (2011) 49:79-84. doi: 10.1016/j.ijbiomac.2011.03.018

34. Shao Z, Shrestha K, Borowski AG, Kennedy DJ, Epelman S, Thomas JD, et al. Increasing Serum Soluble Angiotensin-Converting Enzyme 2 Activity After Intensive Medical Therapy Is Associated With Better Prognosis in Acute Decompensated Heart Failure. J Cardiac Fail (2013) 19:605-10. doi: 10.1016/ j.cardfail.2013.06.296

35. Jia HP, Look DC, Tan P, Shi L, Hickey M, Gakhar L, et al. Ectodomain Shedding of Angiotensin Converting Enzyme 2 in Human Airway Epithelia. Am J Physiol Lung Cell Mol Physiol (2009) 297:L84-96. doi: 10.1152/ ajplung.00071.2009

36. Wysocki J, Ye M, Rodriguez E, Gonzalez-Pacheco FR, Barrios C, Evora K, et al. Targeting the Degradation of Angiotensin II With Recombinant Angiotensin-Converting Enzyme 2: Prevention of Angiotensin IIDependent Hypertension. Hypertension (2010) 55:90-8. doi: 10.1161/ HYPERTENSIONAHA.109.138420

37. Lai ZW, Hanchapola I, Steer DL, Smith AI. Angiotensin-Converting Enzyme 2 Ectodomain Shedding Cleavage-Site Identification: Determinants and Constraints. Biochemistry (2011) 50:5182-94. doi: 10.1021/bi200525y

38. Xu J, Sriramula S, Xia H, Moreno-Walton L, Culicchia F, Domenig O, et al. Clinical Relevance and Role of Neuronal AT1 Receptors in ADAM17Mediated ACE2 Shedding in Neurogenic Hypertension. Circ Res (2017) 121:43-55. doi: 10.1161/CIRCRESAHA.116.310509

39. Kuan TC, Yang TH, Wen CH, Chen MY, Lee IL, Lin CS. Identifying the Regulatory Element for Human Angiotensin-Converting Enzyme 2 (ACE2) Expression in Human Cardiofibroblasts. Peptides (2011) 32:1832-9. doi: 10.1016/j.peptides.2011.08.009

40. Pontoglio M, Barra J, Hadchouel M, Doyen A, Kress C, Bach JP, et al. Hepatocyte Nuclear Factor 1 Inactivation Results in Hepatic Dysfunction,
Phenylketonuria, and Renal Fanconi Syndrome. Cell (1996) 84:575-85. doi: 10.1016/s0092-8674(00)81033-8

41. Pedersen KB, Chhabra KH, Nguyen VK, Xia H, Lazartigues E. The Transcription Factor HNF1alpha Induces Expression of AngiotensinConverting Enzyme 2 (ACE2) in Pancreatic Islets From Evolutionarily Conserved Promoter Motifs. Biochim Biophys Acta (2013) 1829:1225-35. doi: 10.1016/j.bbagrm.2013.09.007

42. Niehof M JB. HNF4alpha Dysfunction as a Molecular Rational for Cyclosporine Induced Hypertension. PloS One (2011) 6:e16319. doi: 10.1371/journal.pone.0016319.t001

43. Semenza GL. Expression of Hypoxia-Inducible Factor 1: Mechanisms and Consequences. Biochem Pharmacol (2000) 59:47-53. doi: 10.1016/s0006-2952 (99)00292-0

44. Zhang R, Wu Y, Zhao M, Liu C, Zhou L, Shen S, et al. Role of HIF-1alpha in the Regulation ACE and ACE2 Expression in Hypoxic Human Pulmonary Artery Smooth Muscle Cells. Am J Physiol Lung Cell Mol Physiol (2009) 297: L631-40. doi: 10.1152/ajplung.90415.2008

45. Clarke NE, Belyaev ND, Lambert DW, Turner AJ. Epigenetic Regulation of Angiotensin-Converting Enzyme 2 (ACE2) by SIRT1 Under Conditions of Cell Energy Stress. Clin Sci (Lond) (2014) 126:507-16. doi: 10.1042/CS20130291

46. Tikoo K, Patel G, Kumar S, Karpe PA, Sanghavi M, Malek V, et al. Tissue Specific Up Regulation of ACE2 in Rabbit Model of Atherosclerosis by Atorvastatin: Role of Epigenetic Histone Modifications. Biochem Pharmacol (2015) 93:343-51. doi: 10.1016/j.bcp.2014.11.013

47. Fernandes T, Hashimoto NY, Magalhaes FC, Fernandes FB, Casarini DE, Carmona AK, et al. Aerobic Exercise Training-Induced Left Ventricular Hypertrophy Involves Regulatory MicroRNAs, Decreased AngiotensinConverting Enzyme-Angiotensin Ii, and Synergistic Regulation of Angiotensin-Converting Enzyme 2-Angiotensin (1-7). Hypertension (2011) 58:182-9. doi: 10.1161/HYPERTENSIONAHA.110.168252

48. Trojanowicz B, Imdahl T, Ulrich C, Fiedler R, Girndt M. Circulating miR-421 Targeting Leucocytic Angiotensin Converting Enzyme 2 Is Elevated in Patients With Chronic Kidney Disease. Nephron (2019) 141:61-74. doi: $10.1159 / 000493805$

49. Lambert DW, Lambert LA, Clarke NE, Hooper NM, Porter KE, Turner AJ. Angiotensin-Converting Enzyme 2 is Subject to Post-Transcriptional Regulation by miR-421. Clin Sci (Lond) (2014) 127:243-9. doi: 10.1042/ CS20130420

50. Chou CH, Chuang LY, Lu CY, Guh JY. Interaction Between TGF-Beta and ACE2-Ang-(1-7)-Mas Pathway in High Glucose-Cultured NRK-52E Cells. Mol Cell Endocrinol (2013) 366:21-30. doi: 10.1016/j.mce.2012.11.004

51. Zhao S, Ghosh A, Lo C-S, Chenier I, Scholey JW, Filep JG, et al. Nrf2 Deficiency Upregulates Intrarenal Angiotensin-Converting Enzyme-2 and Angiotensin 1-7 Receptor Expression and Attenuates Hypertension and Nephropathy in Diabetic Mice. Endocrinology (2018) 159:836-52. doi: 10.1210/en.2017-00752

52. Pang XF, Zhang LH, Bai F, Wang NP, Garner RE, McKallip RJ, et al. Attenuation of Myocardial Fibrosis With Curcumin is Mediated by Modulating Expression of Angiotensin II AT1/AT2 Receptors and ACE2 in Rats. Drug Des Devel Ther (2015) 9:6043-54. doi: 10.2147/dddt.S95333

53. Sánchez-Aguilar M, Ibarra-Lara L, Del Valle-Mondragón L, Rubio-Ruiz ME, Aguilar-Navarro AG, Zamorano-Carrillo A, et al. Rosiglitazone, a Ligand to Ppary, Improves Blood Pressure and Vascular Function Through ReninAngiotensin System Regulation. PPAR Res (2019) 2019:1371758-70. doi: $10.1155 / 2019 / 1371758$

54. Wu L, Zhou PQ, Xie JW, Zhu R, Zhou SC, Wang G, et al. Effects of Yinchenhao Decoction on Self-Regulation of Renin-Angiotensin System by Targeting Angiotensin Converting Enzyme 2 in Bile Duct-Ligated Rat Live. J Huazhong Univ Sci Technolog Med Sci (2015) 35:519-24. doi: 10.107/s1596015-1463-9

55. Liu J, Chen Q, Liu S, Yang X, Zhang Y, Huang F. Sini Decoction Alleviates E. Coli Induced Acute Lung Injury in Mice via Equilibrating ACE-AngII-AT1R and ACE2-Ang-(1-7)-Mas Axis. Life Sci (2018) 208:139-48. doi: 10.1016/ j.lfs.2018.07.013

56. Dhawale VS, Amara VR, Karpe PA, Malek V, Patel D, Tikoo K. Activation of Angiotensin-Converting Enzyme 2 (ACE2) Attenuates Allergic Airway Inflammation in Rat Asthma Model. Toxicol Appl Pharmacol (2016) 306:17-26. doi: 10.1016/j.taap.2016.06.026 
57. Vaduganathan M, Vardeny O, Michel T, McMurray JJV, Pfeffer MA, Solomon SD. Renin-Angiotensin-Aldosterone System Inhibitors in Patients With Covid-19. N Engl J Med (2020) 382:1653-9. doi: 10.1056/NEJMsr2005760

58. Hamming I, van Goor H, Turner AJ, Rushworth CA, Michaud AA, Corvol P, et al. Differential Regulation of Renal Angiotensin-Converting Enzyme (ACE) and ACE2 During ACE Inhibition and Dietary Sodium Restriction in Healthy Rats. Exp Physiol (2008) 93:631-8. doi: 10.1113/expphysiol.2007.041855

59. Ferrario CM, Jessup J, Chappell MC, Averill DB, Brosnihan KB, Tallant EA, et al. Effect of Angiotensin-Converting Enzyme Inhibition and Angiotensin II Receptor Blockers on Cardiac Angiotensin-Converting Enzyme 2. Circulation (2005) 111:2605-10. doi: 10.1161/CIRCULATIONAHA.104.510461

60. Jessup JA, Gallagher PE, Averill DB, Brosnihan KB, Tallant EA, Chappell MC, et al. Effect of Angiotensin II Blockade on a New Congenic Model of Hypertension Derived From Transgenic Ren-2 Rats. Am J Physiol Heart Circ Physiol (2006) 291:H2166-72. doi: 10.1152/ajpheart.00061.2006

61. Ocaranza MP, Godoy I, Jalil JE, Varas M, Collantes P, Pinto M, et al. Enalapril Attenuates Downregulation of Angiotensin-Converting Enzyme 2 in the Late Phase of Ventricular Dysfunction in Myocardial Infarcted Rat. Hypertension (2006) 48:572-8. doi: 10.1161/01.HYP.0000237862.94083.45

62. Li Y, Zeng Z, Cao Y, Liu Y, Ping F, Liang M, et al. Angiotensin-Converting Enzyme 2 Prevents Lipopolysaccharide-Induced Rat Acute Lung Injury via Suppressing the ERK1/2 and NF-kappaB Signaling Pathways. Sci Rep (2016) 6:27911. doi: 10.1038/srep27911

63. Vuille-dit-Bille RN, Camargo SM, Emmenegger L, Sasse T, Kummer E, Jando J, et al. Human Intestine Luminal ACE2 and Amino Acid Transporter Expression Increased by ACE-Inhibitors. Amino Acids (2015) 47:693-705. doi: 10.1007/s00726-014-1889-6

64. Ferrario CM, Jessup J, Gallagher PE, Averill DB, Brosnihan KB, Ann Tallant E, et al. Effects of Renin-Angiotensin System Blockade on Renal Angiotensin(1-7) Forming Enzymes and Receptors. Kidney Int (2005) 68:2189-96. doi: 10.1111/j.1523-1755.2005.00675.x

65. Klimas J, Olvedy M, Ochodnicka-Mackovicova K, Kruzliak P, Cacanyiova S, Kristek F, et al. Perinatally Administered Losartan Augments Renal ACE2 Expression But Not Cardiac or Renal Mas Receptor in Spontaneously Hypertensive Rats. J Cell Mol Med (2015) 19:1965-74. doi: 10.1111/jcmm.12573

66. Wösten-van Asperen RM, Lutter R, Specht PA, Moll GN, van Woensel JB, van der Loos CM, et al. Acute Respiratory Distress Syndrome Leads to Reduced Ratio of ACE/ACE2 Activities and is Prevented by Angiotensin-(1-7) or an Angiotensin II Receptor Antagonist. Yearbook Anesthesiol Pain Manage (2012) 2012:193-6. doi: 10.1016/j.yane.2011.12.013

67. Igase M, Strawn WB, Gallagher PE, Geary RL, Ferrario CM. Angiotensin II AT1 Receptors Regulate ACE2 and Angiotensin-(1-7) Expression in the Aorta of Spontaneously Hypertensive Rats. Am J Physiol Heart Circ Physiol (2005) 289:H1013-9. doi: 10.1152/ajpheart.00068.2005

68. Jin HY, Song B, Oudit GY, Davidge ST, Yu HM, Jiang YY, et al. ACE2 Deficiency Enhances Angiotensin II-Mediated Aortic Profilin-1 Expression, Inflammation and Peroxynitrite Production. PloS One (2012) 7:e38502. doi: 10.1371/journal.pone.0038502

69. Zhong JC, Ye JY, Jin HY, Yu X, Yu HM, Zhu DL, et al. Telmisartan Attenuates Aortic Hypertrophy in Hypertensive Rats by the Modulation of ACE2 and Profilin-1 Expression. Regul Pept (2011) 166:90-7. doi: 10.1016/j.regpep. 2010.09.005

70. Soler MJ, Ye MH, Wysocki J, William J, Lloveras J, Batlle D. Localization of ACE2 in the Renal Vasculature: Amplification by Angiotensin II Type 1 Receptor Blockade Using Telmisartan. Am J Physiol Renal Physiol (2009) 296: F398-405. doi: 10.1152/ajprenal.90488.2008

71. Karam CN, Nuwayri-Salti N, Usta JA, Zwainy DS, Abrahamian RE, Al Jaroudi WA, et al. Effect of Systemic Insulin and Angiotensin II Receptor Subtype-1
Antagonist on Endothelin-1 Receptor Subtype(s) Regulation and Binding in Diabetic Rat Heart. Endothelium (2005) 12:225-31. doi: 10.1080/ 10623320500476450

72. Keidar S, Gamliel-Lazarovich A, Kaplan M, Pavlotzky E, Hamoud S, Hayek T, et al. Mineralocorticoid Receptor Blocker Increases Angiotensin-Converting Enzyme 2 Activity in Congestive Heart Failure Patients. Circ Res (2005) 97:946-53. doi: 10.1161/01.RES.0000187500.24964.7A

73. Ding W, Li X, Wu W, He H, Li Y, Gao L, et al. Aliskiren Inhibits Angiotensin II/angiotensin 1-7(Ang II/Ang1-7) Signal Pathway in Rats With Diabetic Nephropathy. Xi Bao Yu Fen Zi Mian Yi Xue Za Zhi (2018) 34:891-5.

74. Gembardt F, Sterner-Kock A, Imboden H, Spalteholz M, Reibitz F, Schultheiss HP, et al. Organ-Specific Distribution of ACE2 mRNA and Correlating Peptidase Activity in Rodents. Peptides (2005) 26:1270-7. doi: 10.1016/ j.peptides.2005.01.009

75. Harada E, Yoshimura M, Yasue H, Nakagawa O, Nakagawa M, Harada M, et al. Aldosterone Induces Angiotensin-Converting-Enzyme Gene Expression in Cultured Neonatal Rat Cardiocytes. Circulation (2001) 104:137-9. doi: 10.1161/01.cir.104.2.137

76. Robert V, Heymes C, Silvestre JS, Sabri A, Swynghedauw B, Delcayre C. Angiotensin AT1 Receptor Subtype as a Cardiac Target of Aldosterone- Role in Aldosterone-Salt-Induced Fibrosis. Hypertension (1999) 33:981-6. doi: 10.1161/01.hyp.33.4.981

77. Turgeon RD, Zieroth S, Bewick D, Chow CM, Clarke B, Cowan S, et al. Use of Renin-Angiotensin System Blockers During the COVID-19 Pandemic: Early Guidance and Evolving Evidence. Can J Cardiol (2020) 36(8):1180-2. doi: 10.1016/j.cjca.2020.05.033

78. Li Y, Zhou W, Yang L, You R. Physiological and Pathological Regulation of ACE2, the SARS-CoV-2 Receptor. Pharmacol Res (2020) 157:104833. doi: 10.1016/j.phrs.2020.104833

79. Caserta LC, Mitchell PK, Plocharczyk E, Diel DG. Identification of a SARSCoV-2 Lineage B1.1.7 Virus in New York Following Return Travel From the United Kingdom. Microbiol Resour Announc (2021) 10(9):e00097-21. doi: 10.1128/MRA.00097-21

80. Wise J. Covid-19: The E484K Mutation and the Risks it Poses. BMJ (2021) 372:n359. doi: 10.1136/bmj.n359

81. Rahimi F, Abadi ATB. Emergence of the Delta Plus Variant of SARS-CoV-2 in Iran. Gene Rep (2021) 101341. doi: 10.1016/j.genrep.2021.101341

82. Derington CG, Cohen JB, Mohanty AF, Greene TH, Cook J, Ying J, et al. Angiotensin II Receptor Blocker or Angiotensin-Converting Enzyme Inhibitor Use and COVID-19-Related Outcomes Among US Veterans. PloS One (2021) 16:e0248080. doi: 10.1371/journal.pone.0248080

Conflict of Interest: The authors declare that the research was conducted in the absence of any commercial or financial relationships that could be construed as a potential conflict of interest.

Publisher's Note: All claims expressed in this article are solely those of the authors and do not necessarily represent those of their affiliated organizations, or those of the publisher, the editors and the reviewers. Any product that may be evaluated in this article, or claim that may be made by its manufacturer, is not guaranteed or endorsed by the publisher.

Copyright (C) $2021 \mathrm{Hu}$, Liu and Lu. This is an open-access article distributed under the terms of the Creative Commons Attribution License (CC BY). The use, distribution or reproduction in other forums is permitted, provided the original author(s) and the copyright owner(s) are credited and that the original publication in this journal is cited, in accordance with accepted academic practice. No use, distribution or reproduction is permitted which does not comply with these terms. 